\title{
3D Reconstructions of Cimmerian Bosporus Painted Crypts
}

\author{
Elena Logdacheva \\ St.-Petersburg State \\ University \\ $49,10^{\text {th }}$ Line V.O. \\ St. Petersburg \\ 199178 Russia \\ elogdacheva@gmail.com
}

\author{
Yuri Vinogradov \\ Institute for the History of \\ Material Culture of RAS \\ 18, Palace emb. \\ St. Petersburg \\ 191186, Russia \\ vincat2008@yandex.ru
}

\author{
Sergei Shvemberger \\ St.-Petersburg State \\ University \\ 49, $10^{\text {th }}$ Line V.O. \\ St. Petersburg \\ 199178 Russia \\ shvemberger@gmail.com
}

\author{
Nikolay Borisov \\ St.-Petersburg State \\ University \\ 49, $10^{\text {th }}$ Line V.O. \\ St. Petersburg \\ 199178 Russia \\ nikborisov@gmail.com
}

\begin{abstract}
The authors present $3 d$ reconstructions of the painted tombs of Cimmerian Bosporus, state, which existed in the North Black Sea area in VI century B.C. - V century A.D. Crypts, was found and investigated by Russian historians in second half of XIX - beginning of XX centuries. Reconstructions are executed on the basis the archive materials, which are stored in the Institute of Material Culture of Russian Academy of Sciences in St.-Petersburg. Crypts were lost because of political events at the beginning of $X X$ century. Of special interest among available material, on basis of which was conducted computer reconstruction, are the aquarelles and gouaches of Russian artists XIX - XX of centuries The computer reconstructions of crypts are executed with the aid of the application 3Ds Max.
\end{abstract}

With the visual materials of Cimmerian Bosporus Painted Crypts project it is possible to become acquainted on project's site http://www.bosporuscrypt.ru/ (in Russian) and on the site http://www.3DMultimediaLab.com

Ancient Greece. Bosporan Kingdom. 3D Reconstructions. Computer Art.

\section{CRYPTS OF THE CIMMERIAN BOSPORUS FOUND AND LOST}

The Cimmerian Bosporus (the ancient name for the Strait of Kerch) is one of the most important centres of the Greek colonization on the Northern coast of the Black Sea. It was here that the Bosporus Kingdom, the largest one in the region, had been formed and had endured for 1000 years $\left(5^{\text {th }}\right.$ cent. $B C-5^{\text {th }}$ cent. $\left.A D\right)$. Its principal territory included the Eastern Crimea (the South of the Ukraine) and the Taman Peninsular (the South of Russia). According to the geographic notions of the Antiquity, the former part was located in Europe (the European Bosporus) and the latter one in Asia (the Asian Bosporus). The state incorporated the formerly independent Greek city states of the coastal area, as well as a number of local Barbarian tribes (Sindi, Toreatae etc.). The capital of the conglomerate was the city of Panticapaeum, its ruins are still to be found within the limits of the present day Kerch, around Mount Mithridates.

The culture of the Bosporus Kingdom is believed to be the most successful synthesis of the Greek and the Barbarian cultures to be found in the Northern Black Sea area. It offers us a considerable number of the classic antiquity monuments, duly included into the treasury of the world's cultural heritage. One of the most outstanding types of monuments preserved on the banks of the Strait of Kerch is, for sure, the painted burial crypts. The earliest ones date back to the $4^{\text {th }}$ cent. BC. The largest group, dating back to the $1-3 r d$ cents. $A D$, is to be found on the Northern slope of Mount Mithridates. The burial chambers chiselled out in solid rock are sometimes referred to as The Catacombs; they have all been looted -- apparently, back in the times of the Antiquity. The vaults of the crypts were adorned with various images, basically representing the blissful existence of the dead in the after world, as well as the ways of attaining that world. The discovery of these incredible monuments was a major achievement of the Russian archaeologists. The first painted crypt was excavated in Kerch by A. B. Ashik in 1842.

Later in the $19^{\text {th }}$ cent., the scholars paid particular attention to the painted crypts: plans were charted, images copied, detailed descriptions made etc. Amid the archaeologists who made a major contribution to the studies of the crypts are the directors of the Kerch Museum of the Antiques: A. E. Lucenko, F. I. Gross, K. E. Dumberg (Figure 1). 
The data of the period are currently preserved in the scientific archives of the Institute of the History of the Material Culture, Russian Academy of Science, St. Petersburg. Amid the others (architectural plans, verbal descriptions, photographs) a special place belongs to the copies made in mixed media technique (water colour, gouache) on a fairly large scale.

A major contribution to the structuring of the data was made by Professor Y. A. Kulakovsky from the University of Kiev. And the ultimate summing up of the extensive data is, to the day, the book of the renowned Antiquity scholar M. I. Rostovtsev, The Ancient Decorative Paintings in the South of Russia (1914); we will soon be celebrating its centennial anniversary.

Unfortunately, the much-needed preservation of these invaluable monuments was not organized on a timely basis. They were buried under the city's garbage, and even the location of some of them on Mt. Mithridates had been eliminated from memory. Obviously, the crypts, especially the painted ones, attracted looters as well as archaeologists. Kerch even had a professional guild of the tomb raiders, or the so-called 'lucky devils'. The archaeologists had to fight them, sometimes almost to the death. But there were other mishaps in store for the ancient monuments of the Bosporus. The tumult of the Civil War that broke out in Russia after the 1917 revolution, as well as the fighting of the World War II that affected the area twice, brought considerable damage to a number of monuments. As for the painted crypts, the worst sufferer was the best known one, the so-called Demeter Crypt, and yet, it was preserved. Today, the scholars and the visitors coming to Kerch can access only one out of ca. 30 crypts that were studied to various extents in the $19^{\text {th }}$ cent.: the Demeter Crypt.

The other priceless monuments that are so invaluable for the understanding of the cultural and historic development of the Bosporus are all but lost. Actually, that is the main reason why the computer reconstruction is essential. The 3D models would offer a more or less adequate idea of the looks of the crypts, the location of the paintings, their correlation etc. Regrettably, by the most part it is the only way for our contemporaries to 'enter' the ancient crypts of the Bosporos, to appreciate their unique interiors, to admire the paintings.

In recent times, the interest of the archaeologists from various countries (Russia, the Ukraine, Switzerland) in the painted crypts of the Bosporos has been surging. To reinforce this process, we decided to make an attempt to create several reconstructions of the crypts, using the copies made by the late 19th - early 20th cents. artists (F.
I. Gross, M. V. Farmakovsky and others (Figure 4)) and the modern 3D graphics technique. On one hand, we would like to attract the attention of the academic community to the crypts, on the other, to put the results online and thus make these incredible monuments accessible to the general public, i.e. to anyone interested in the history and culture of the Antiquity.

To the day, we have created the computer reconstructions of two painted crypts.

\section{1872 CRYPT (STASOVSKY)}

One of the most renowned monuments of the Northern Black Sea area is the crypt where the ancient paintings have been preserved, discovered on the Northern slope of Mt. Mithridates in Kerch in 1872 and described by the Russian art critic and scholar V. V. Stasov. The crypt, dug in the earth, was of the shape typical for the structures. A narrow passage leads into the burial chamber from the North. The chamber has the shape of an irregular rectangle, the height is also irregular, somewhat increased towards the back (Southern) wall.

The paintings of the Stasovsky Crypt are a combination of two styles, inlay (the earlier one) and floral (the latter one). In all probability, the crypt should be dated back to the early $2^{\text {nd }}$ cent. $A D$. (Figure 5).

\section{1973 DOUBLE CRYPT}

Another important monument of the Bosporus culture of the early $A D$ period is the double crypt discovered on the Northern slope of Mt. Mithridates in Kerch in 1873. The structure includes two burial chambers linked by a narrow passage. Both are painted in the highly decorative or, as it is also called, floral manner. M. I. Rostovtsev dates the 1873 crypt back to the end of the $1^{\text {st }}-$ first half of the $2^{\text {nd }}$ cent. $A D$.

Beyond any doubt, the overall idea of the ornamental composition of the Double Crypt is the declaration of the idea of resurrection in afterlife and the description of the blissful existence that the heroes enjoy in the care of the omnipotent gods (Figure 3).

\section{COMPUTER RECONSTRUCTIONS OF THE CRYPTS}

Computer reconstruction of the crypts (authors - Dr. Yu. Vinogradov, E. Logdacheva, S. Shvemberger) was performed using the standard methods of $3 D$ 
modelling and animation (the popular 3Ds Max Autodesk application was used). The reconstruction of the 1872 crypt was based on the watercolour copies of the paintings made by M. V. Farmakovsky in 1909 (Figure 6 and 7). Copies made by F. I. Gross right after the discovery of the 1873 Double Crypt were used for the reconstruction of that monument (Figure 2).

Actually, M. I. Rostovtsev had declared the copies of F. I. Gross inaccurate, and thus in 1911 commissioned M. V. Farmakovsky to make his own copies of the most interesting fragments, adding precision to certain details. However, by the time the frescos had deteriorated, and certain figures had been destroyed by the raiders. Thus the copies by F. I. Gross have captured the composition in full reason, we have taken them for the main base of our computer model; yet, in the future the model will be updated using the data by M. V. Farmakovsky.

Another important issue is that the copies by $\mathrm{F}$. I. Gross and M. V. Farmakovsky are drastically different in manner, in technique and, apparently, in the attitude to the original. The copies by F. I. Gross are illuminated drawings; most probably, he was a draughtsman rather than an artist. The copies by M. V. Farmakovsky are much more pictorial, they are made with large, free, pastoso strokes. The artist tried to capture the most minute details of the originals, that by the most part had escaped the attention of F. I. Gross. On the other hand, we cannot be sure that the small details in question are authentic, since the surface of the walls is very rough and the original paintings are by the most part quite crude.

And yet, while making our reconstructions, we tried to stick as closely as possible to the copies (by F. I.
Gross for the 1873 Double Crypt and by M. V. Farmakovsky for the 1872 crypt).

The reconstruction of the 1873 crypt based on the copies by F. I. Gross appears to be more 'accurate', the walls of the crypt are level, the angle lines straight. By contrast, the 1872 crypt reconstructed on the base of the copies by M. V. Farmakovsky seems to be a structure without a single straight line. It looks more like a cave, with the vaults smoothed in a very perfunctory way (even though the crypt is by no means a cave). Could these differences indicate that the crypts were built in two different ways, or do the paintings reflect the two individual styles of two different artists? We hope to come up with an explanation, as we proceed with the reconstruction of the other crypts and analyze more data. Apparently, the second reconstruction is not devoid of a certain subjective touch. That is yet another reminder of the fact that a reconstruction of a lost monument is but a more or less plausible version of the original. To recreate the definitive original look is a dream that would hardly come true.

In the upcoming years our group plans to create the computer reconstructions of all those painted crypts of the Bosporus that have copies of the paintings preserved in the scientific archives of the Institute of the History of the Material Culture, Russian Academy of Science. The most important ones are the painted crypts of Bolshaya Bliznitsa, the Mount Vasurinskaya complex, the Demeter Crypt. The further goal are the detailed studies of all the monuments in regards of their chronology, specific features of the painting style, structuring of the pictorial composition, semantics of the images etc.

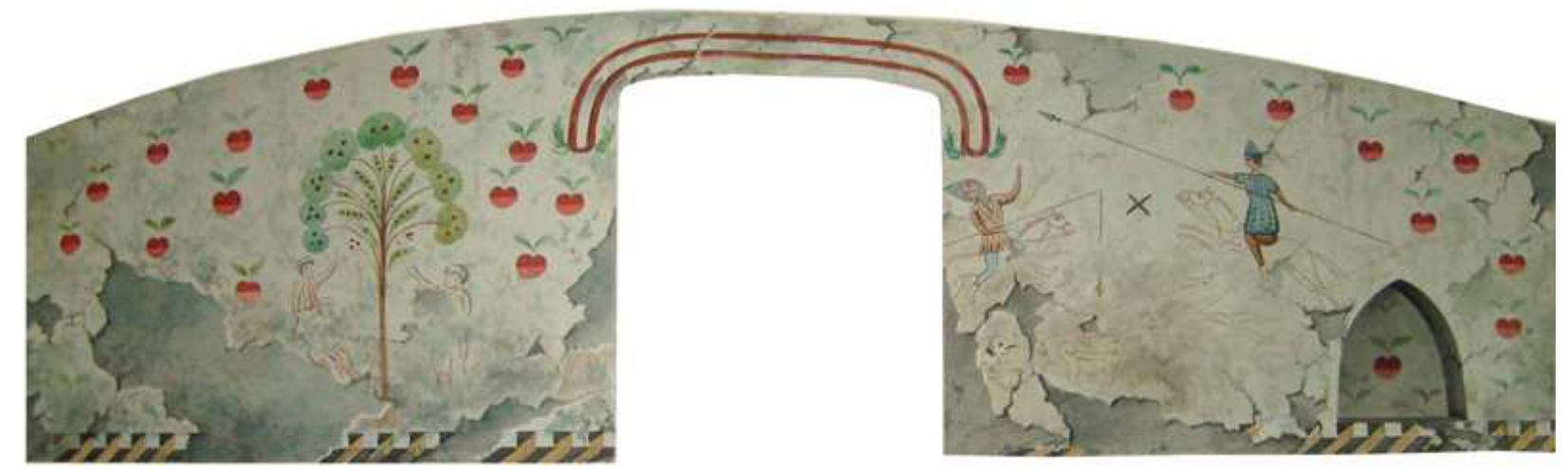

Figure 1: F. Gross. 1873 Double Crypt. Mixed media 
3D Reconstruction of Cimmerian Bosporus Painted Crypts

Elena Logdacheva, Yuri Vinogradov, Sergei Shvemberger \& Nikolay Borisov

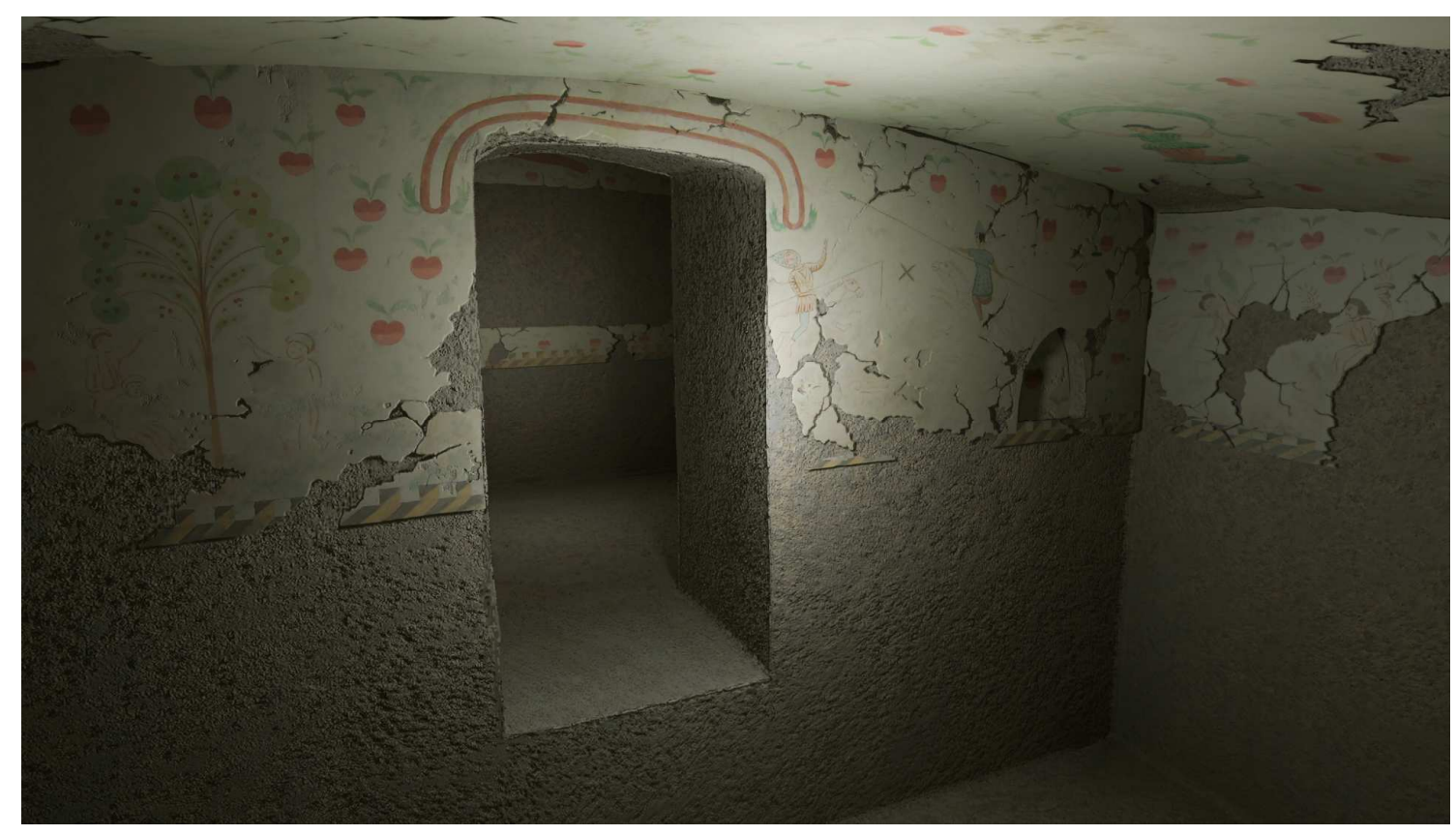

Figure 2: E. Logdacheva, S. Shvemberger, Yu. Vinogradov. 1873 Double Crypt. Computer reconstruction

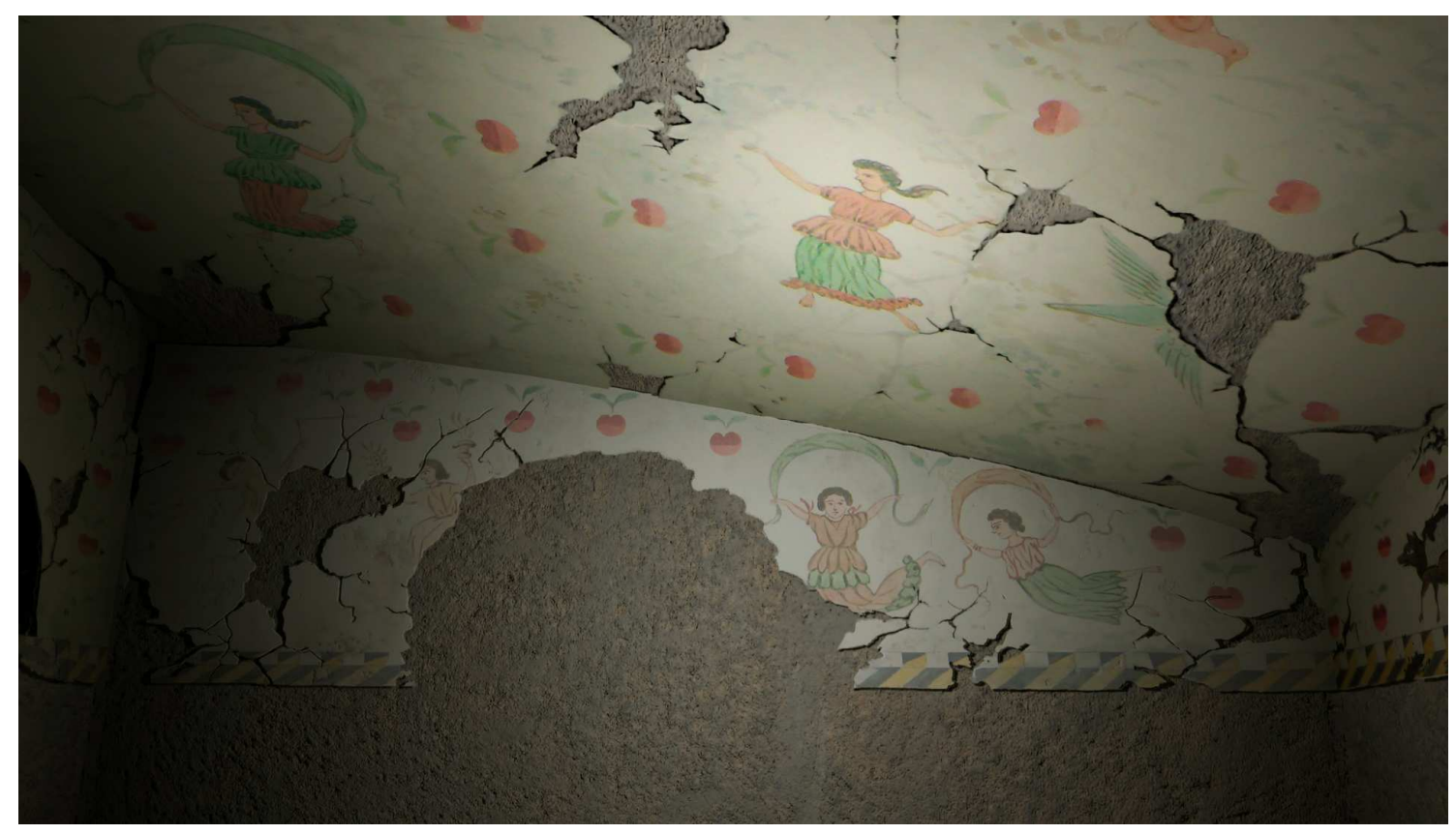

Figure 3: E. Logdacheva, S. Shvemberger, Yu. Vinogradov. 1873 Double Crypt. Computer reconstruction 
3D Reconstruction of Cimmerian Bosporus Painted Crypts

Elena Logdacheva, Yuri Vinogradov, Sergei Shvemberger \& Nikolay Borisov

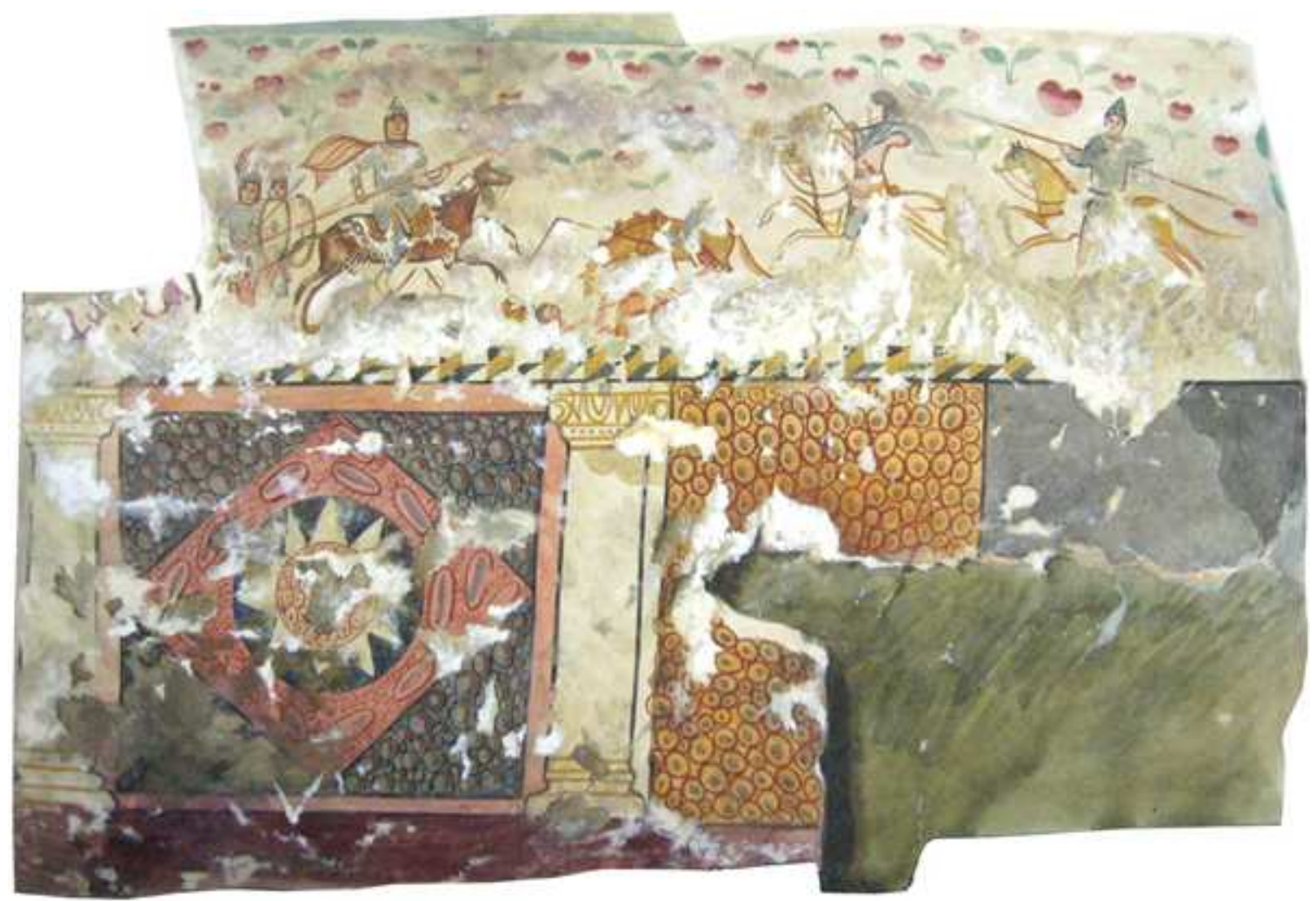

Figure 4: M. Farmakovsky 1872 Crypt (Stasovsky). Mixed media

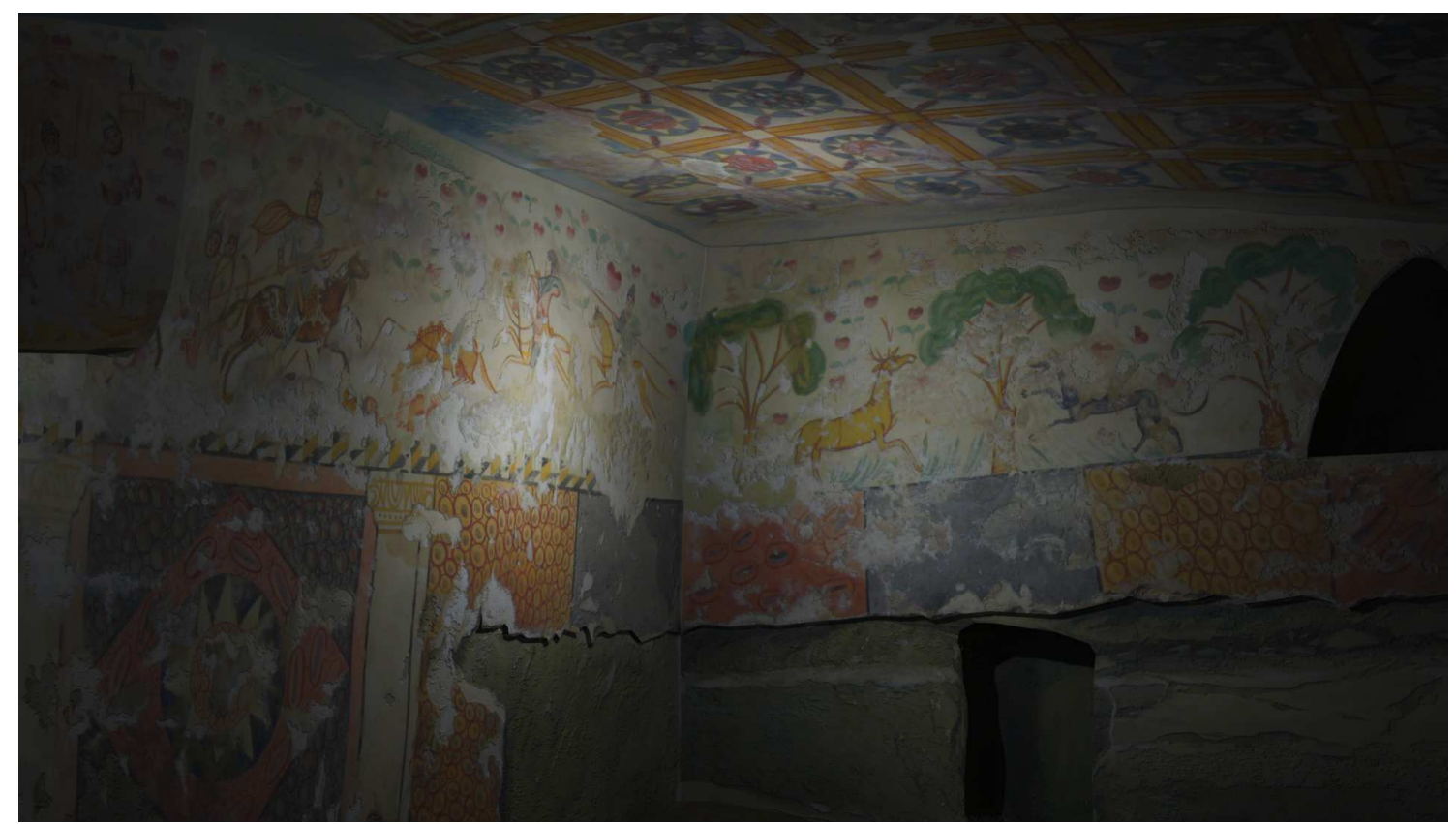

Figure 5: E. Logdacheva, S. Shvemberger, Yu. Vinogradov. 1872 Crypt (Stasovsky). Computer reconstruction 


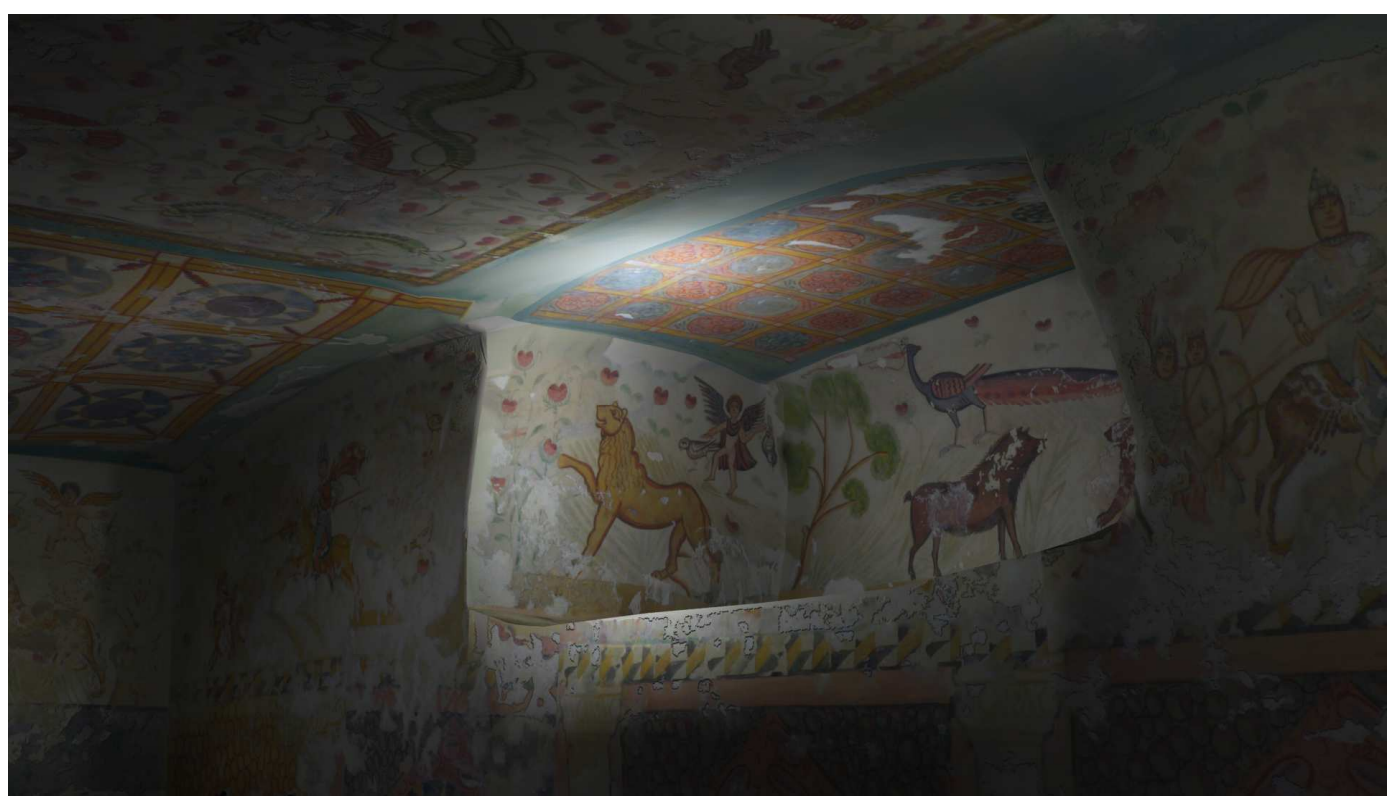

Figure 6: E. Logdacheva, S. Shvemberger, Yu. Vinogradov. 1872 Crypt (Stasovsky). Computer reconstruction

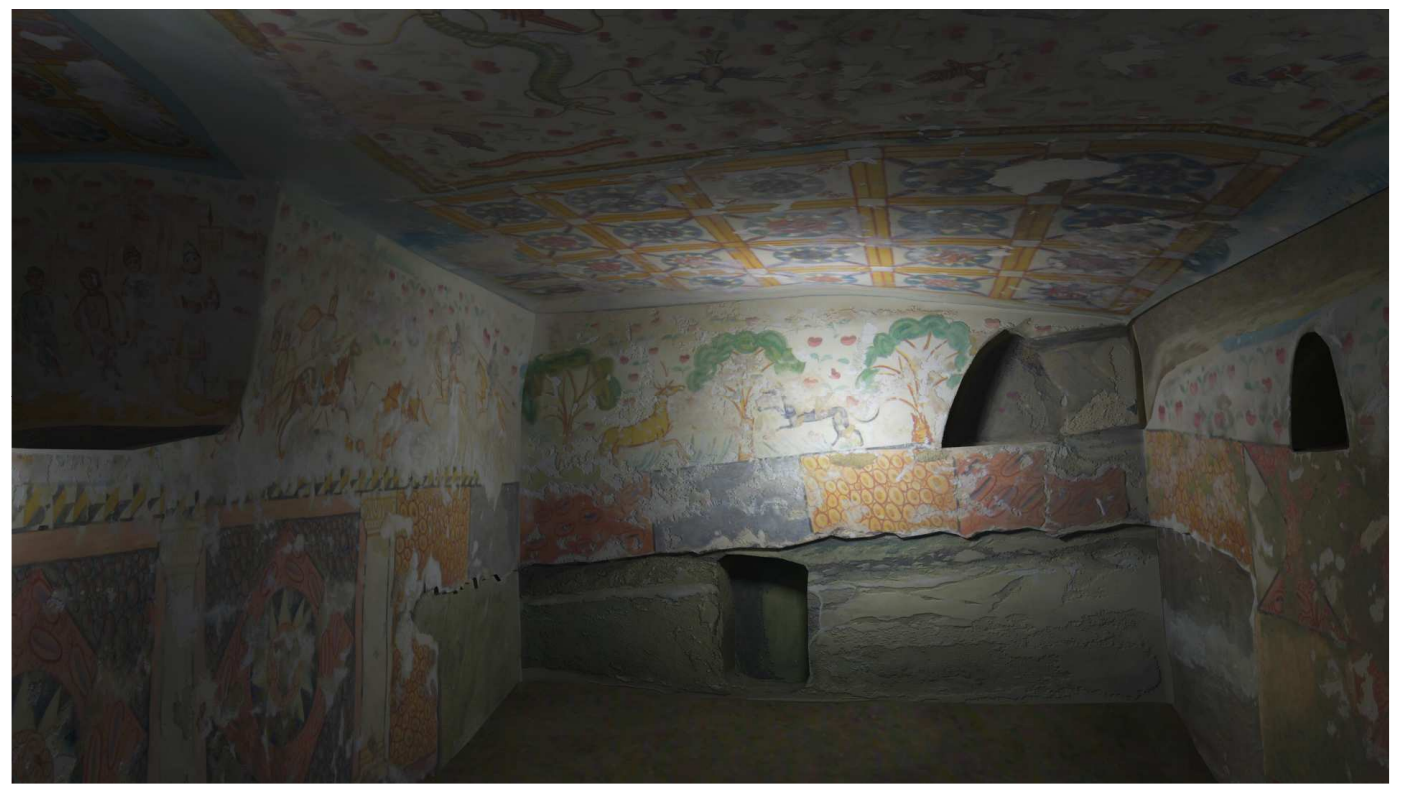

Figure 7: E. Logdacheva, S. Shvemberger, Yu. Vinogradov. 1872 Crypt (Stasovsky). Computer reconstruction

\section{ACKNOWLEDGEMENTS}

This work was supported by the grant "Multimedia Information System Cimmerian Bosporus Painted Crypts" N10-04-12106B of Russian Foundation for Humanitarian Research.

\section{REFERENCES}

Rostovtsev, M.I. (1914) Decorative Paintings of Classical Period in South Russia. Saint Petersburg (in Russian).
Shvemberger, S., Goroncharovskij, V. and Szherbacov, P. (2006) 3Ds Max. Art Modelling and Special Effects. BHV-Petersburg, St.-Petersburg (in Russian).

Vinogradov Yu. A. and Shvemberger S. V. (2009) New Perspectives in Study of Bosporus Painted Crypts. The Phenomenon of Bosporan Kingdom: Arts at the Periphery of Classical World, Proceedings of International Conference, 151-155, Saint Petersburg (in Russian). 